\title{
High-frequency regeneration of plants in vitro from seedling-derived apical bud explants of Tilia mandshurica Rupr. \& Maxim
}

\author{
Tae-Dong Kim • Nam-Ho Kim • Eung-Jun Park • Na-Nyum Lee
}

Received: 12 August 2020 / Revised: 23 December 2020 / Accepted: 29 December 2020

(C) Korean Society for Plant Biotechnology

\begin{abstract}
This work describe an efficient method for the shoot induction and plant regeneration of seedling-derived apical bud explants of Tilia mandshurica Rupr. \& Maxim. The highest rate of shoot induction (82.2\%) was obtained when apical bud explants from juvenile seedlings ( 5 months old) were cultured on Murashige and Skoog (MS) medium containing $1.0 \mathrm{mg} / \mathrm{L}$ 6-benzylaminopurine (BAP). However, apical bud explants obtained from mature trees (12 years old) did not produce any shoots, even with BAP supplementation. Among the three cytokinins tested for shoot multiplication (BAP, zeatin, and kinetin), BAP was the most effective; the highest number of shoots per explant (2.1) was observed on MS medium supplemented with $1.0 \mathrm{mg} / \mathrm{L}$ BAP. In contrast, the longest average shoot length $(3.0 \mathrm{~cm})$ was observed after growth on MS medium with $2.0 \mathrm{mg} / \mathrm{L}$ zeatin. No multiplication occurred when apical bud explants were cultured with kinetin-supplemented media. During rooting of in vitro-elongated shoots, the highest rooting rate $(100 \%)$ was observed in half-strength MS medium supplemented with $0.5 \sim 1.0 \mathrm{mg} / \mathrm{L}$ indole-3-butyric acid (IBA) or $3.0 \mathrm{mg} / \mathrm{L}$ 1-naphthaleneacetic acid (NAA). During the acclimatization process, plantlets that were rooted on the IBA $(0.5 \mathrm{mg} / \mathrm{L})$ supplemented medium had the highest survival rate $(100 \%)$ and maximum root length $(18.5 \mathrm{~cm})$. These findings suggest that a low concentration $(0.5 \mathrm{mg} / \mathrm{L})$ of IBA is appropriate for the rooting and acclimatization of T. mandshurica. Plants were successfully transferred to the greenhouse with a $100 \%$ survival rate. This protocol will be useful for the large-scale
\end{abstract}

T.-D. Kim $(\bowtie) \cdot$ E.-J. Park $\cdot$ N.-N. Lee

Forest Biotechnology Division, National Institute of Forest Science, Suwon 16631, Korea

e-mail: ktd747@korea.kr

N.-H. Kim

Chuncheon Branch Office, National Forest Seed and Variety

Center, Chuncheon 24219, Korea propagation of Tilia species.

Keywords Tilia mandshurica, apical bud culture, shoot induction, root induction, BAP, IBA

\section{Introduction}

Tilia is a genus of about 30 species of trees or bushes, sometimes referred to as lime bushes, that is native across many temperate regions of the Northern Hemisphere. Tilia species are mostly large, deciduous trees that typically reach a height of 20 to $40 \mathrm{~m}$ and have oblique-cordate leaves 6 to $20 \mathrm{~cm}$ across. The tree produces fragrant, nectar-producing flowers, as well as lime blossoms, which are used as a medicinal herb. Tilia is an important honey plant for beekeepers, producing a very pale, but richly flavored, monofloral honey. The flowers are also used for herbal teas and tinctures, which are particularly popular in Europe and in North American herbal medicine practices. Tilia species have taken hold as a crop of interest for both the honey and timber industries, underscoring a need for the development of efficient methods for large-scale propagation (Yoon et al. 2005; Yang et al. 2011; Panchev 2019; Yang et al. 2020).

In Tilia species such as T. mandshurica, propagation through seeds is difficult because of a low germination rate (approximately 10 16\%) and an extremely hard seed coating that can delay germination for up to two years. Further, cutting propagation is not efficient due to the resulting poor development of root systems (Lee and Suh 1989; Morsink and Smith 1974, 1975).

To overcome these difficulties, in vitro culture techniques for plant regeneration have become attractive methods for the propagation of plants. Generally, plant regeneration systems based on apical and axillary bud culture are the most effective method of in vitro propagation. Indeed, 
micropropagation protocols through axillary bud culture of $T$. cordata and $T$. amurensis have previously been reported (Youn and Ohba 1990; Youn et al. 1998). A procedure for plant regeneration from zygotic embryos via somatic embryogenesis has been also developed in T. cordata, $T$. platyphyllos, T. mandshurica, and T. amurensis (Chalupa 1990; Kim et al. 1988; Moon and Youn 1996; Üçler and Mollamehmetoğlu 2001; Kim et al. 2006, 2007). However, plant regeneration through somatic embryogenesis of $T$. mandshurica is not an efficient solution for large-scale propagation because the germination rate of somatic embryos is rather low (10\%) (Moon and Youn 1996). Other than these few reports, there have been no publications describing tissue culture-based micropropagation of $T$. mandshurica.

The aim of the current study was to optimize a protocol for efficient shoot induction and plant regeneration from seedling-derived apical bud explants of T. mandshurica, with a goal of developing an efficient propagation strategy suitable for industrial application.

\section{Materials and Methods}

Plant materials

Apical bud explants were excised from mature 12-year-old trees growing in the nursery of the National Institute of Forest Science and from juvenile 5-month-old seedlings obtained from the National Forest Seed and Variety Center, Korea. Shoot tip segments $(1.0 \sim 1.5 \mathrm{~cm}$ long), each containing an apical bud, were disinfected in $70 \%$ ethanol for $1 \mathrm{~min}$ and then disinfected in $1 \%$ sodium hypochlorite solution for $1 \mathrm{~min}$. After that, they were rinsed with sterile water five times.

Effect of BAP on shoot induction from juvenile and mature sources

During the juvenile phase, shoot tip segments (approximately $1.0 \mathrm{~cm}$ and containing one apical bud) were taken from seedlings that were maintained in a culture room. During the mature phase, shoot tip segments (approximately $1.5 \mathrm{~cm}$ containing one apical bud) were excised from recent branches of trees grown in the nursery. Mature and juvenile explants were both inoculated in MS (Murashige and Skoog, 1962) medium supplemented with various concentrations (0.0, 0.5, 1.0, and $2.0 \mathrm{mg} / \mathrm{L}$ ) of 6-Benzylaminopurine (BAP). Media were solidified with $0.3 \%$ Gelrite $^{\mathrm{TM}}$ powder and adjusted to $\mathrm{pH} 5.8$ before autoclaving for $15 \mathrm{~min}$ at $121^{\circ} \mathrm{C}$.
After inoculation, cultures were incubated at $25 \pm 2^{\circ} \mathrm{C}$ under a 16-h photoperiod with a light intensity of 2,000 lux from white fluorescent tubes.

Effect of cytokinins (BAP, zeatin, or kinetin) on shoot multiplication

The apical portion of the shoot obtained from juvenile apical bud cultures was used for multiple shoot induction. Excised shoot tip explants were placed on MS medium that was supplemented with various concentrations $(0.0$, $0.5,1.0$, and $2.0 \mathrm{mg} / \mathrm{L}$ ) of BAP, zeatin or kinetin. Ten explants were established for each treatment group. Each experiment was replicated three times, for a total of 30 explants per treatment condition. After 8 weeks of culture, the number of shoots per explant was recorded.

\section{Effect of auxins (IBA or NAA) on in vitro rooting}

For rooting, shoots approximately $2 \mathrm{~cm}$ in length were excised and placed vertically on half-strength MS medium supplemented with various concentrations $(0.0,0.5,1.0$, 2.0 , and $3.0 \mathrm{mg} / \mathrm{L}$ ) of IBA (indole-3-butyric acid) or NAA (1-naphthaleneacetic acid). Ten explants were established for each treatment group. Each treatment was replicated three times. After 3 weeks of culture, the rooting percentage, mean number of roots, and mean root length were recorded.

Acclimatization of plantlets rooted on auxin (IBA or NAA)supplemented media

Plantlets that had been rooted on auxin (IBA or NAA)supplemented and auxin-free media were transferred into plastic containers $(54 \times 28 \times 6.5 \mathrm{~cm})$ containing artificial soil mixture [perlite, vermiculite, peat moss 1:1:1 (v/v)] and were acclimated for 4 weeks at a high relative humidity (80-90\%). After 4 weeks, the survival rate and root length of plantlets were measured. Twenty plantlets were planted in soil in plastic pots and transferred to the greenhouse, and each experiment was performed three times.

Statistical analysis

Statistical analysis was performed using the SAS software package (SAS Enterprise Guide 7.1). Means and standard errors were used throughout and the statistical significance of mean values was assessed using ANOVA or Duncan's multiple range tests at $P<0.05$. 


\section{Results and Discussion}

Shoot induction from juvenile and mature sources

To induce shoots from apical buds, apical bud explants that had been excised from juvenile seedlings and mature trees were cultured on MS medium supplemented with different concentrations of BAP $(0.0,0.5,1.0$, and $2.0 \mathrm{mg} / \mathrm{L})$. As shown in Table 1, the highest rate of shoot induction $(82.2 \%)$ was obtained when apical bud explants from juvenile seedlings were cultured on the medium containing $1.0 \mathrm{mg} / \mathrm{L}$ BAP. The lowest concentration of BAP $(0.5$ $\mathrm{mg} / \mathrm{L}$ ) had the lowest induction rate of shoots $(51.0 \%)$. The control medium without BAP resulted in relatively poor shoot induction $(16.4 \%)$. None of the apical bud explants taken from the mature tree developed shoots when cultured on MS medium with or without BAP.

After 6 weeks of culture, apical bud sprouts and shoot growth were observed in apical bud explants taken from the juvenile seedlings. The bud sprouting process started after 3 weeks of culture, and the apical buds subsequently grew actively and developed into shoots by 6 weeks of culture (Fig. 1A). However, apical bud explants from the mature tree did not develop shoots; they turned into brown in colour and died within the culture period (Fig. 1B). In the past, studies suggested that the organogenic potential of mature plant material is lower than that of juvenile plants (Basto ea al. 2012). Indeed, Moon et al. (2002) previously reported that juvenile explants (1-year-old seedlings) produced better shoot proliferation and growth from axillary bud explants of Corylopsis coreana than explants from mature, 10-year-old trees. Srinidhi et al. (2008) reported that nodal explants excised from the juvenile seedlings (1.5-year-old) of Azadirachta indica were more effective

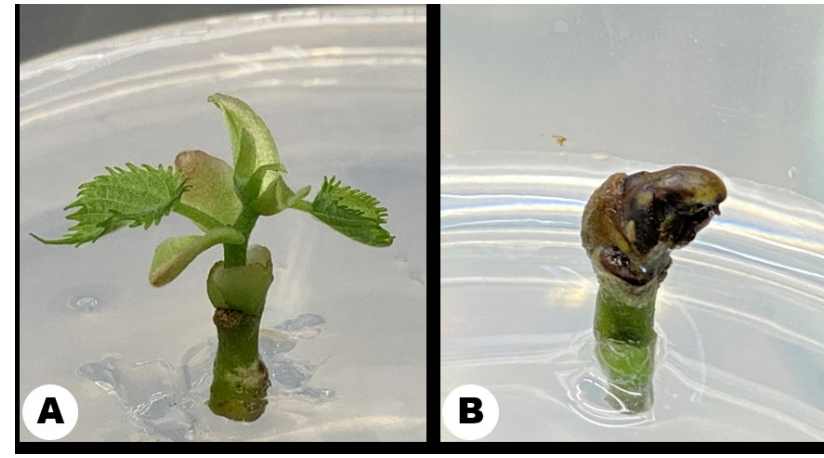

Fig. 1 The induction of shoots from apical buds of Tilia mandshurica on Murashige and Skoog (MS) medium supplemented with $1.0 \mathrm{mg} / \mathrm{L}$ 6-benzylaminopurine (BAP) after 6 weeks of culture. Apical bud explants were taken from 5-month-old seedlings (A) and 12-year-old trees (B)

for shoot induction and rooting than the explants excised from the mature trees (15-year-old). Further, Basto et al. (2012) observed the highest organogenic potential in nodes from juvenile (7-18 month-old) trees and found that material from mature trees $(10 \sim 20$ year-old) had limited organogenesis. Similarly, Tawfik et al. (2020) reported axillary shoot induction from nodal explants excised from in vitro-grown juvenile seedlings (5-week-old) of Koelreuteria bipinnata, however the nodal explants from mature trees (20-year-old) did not develop any axillary shoots. The results from the present study are in good agreement with these prior works, showing that shoot induction from apical bud explants of $T$. mandshurica was observed only in those explants excised from juvenile seedlings (5-month-old). In contrast, none of the apical bud explants obtained from mature trees (12-year-old) produced any shoots. These results indicate that the apical buds of juvenile seedlings (5-month-old) are the best explant source for the in vitro shoot proliferation of $T$. mandshurica.

Table 1 Effect of different concentrations of 6-benzylaminopurine (BAP) on shoot induction in apical bud explants from juvenile seedlings (5 months old) and mature trees (12 years old) after 6 weeks of culture

\begin{tabular}{|c|c|c|}
\hline Explant source & $\begin{array}{c}\text { Concentration of BAP } \\
(\mathrm{mg} / \mathrm{L})\end{array}$ & $\begin{array}{c}\text { Shoot induction } \\
(\%)\end{array}$ \\
\hline \multirow{4}{*}{ 5-month-old seedling } & 0.0 & $16.4 \pm 1.0 \mathrm{~d}$ \\
\hline & 0.5 & $51.0 \pm 1.4 \mathrm{c}$ \\
\hline & 1.0 & $82.2 \pm 1.1 \mathrm{a}$ \\
\hline & 2.0 & $65.6 \pm 1.2 b$ \\
\hline \multirow{4}{*}{ 12-year-old tree } & 0.0 & - \\
\hline & 0.5 & - \\
\hline & 1.0 & - \\
\hline & 2.0 & - \\
\hline
\end{tabular}

Mean separation within columns by Duncan's multiple range test at the $5 \%$ level. 
Table 2 Effect of cytokinin type and concentration on shoot multiplication in Tilia mandshurica after 6 weeks of culture

\begin{tabular}{|c|c|c|c|}
\hline \multicolumn{2}{|c|}{$\begin{array}{l}\text { Cytokinin } \\
(\mathrm{mg} / \mathrm{L})\end{array}$} & $\begin{array}{c}\text { Average number of shoots } \\
\text { per explant }\end{array}$ & $\begin{array}{l}\text { Length of shoots } \\
(\mathrm{cm})\end{array}$ \\
\hline \multicolumn{2}{|c|}{ Control } & $1.0 \pm 0.0 \mathrm{~d}$ & $1.3 \pm 0.1 \mathrm{e}$ \\
\hline \multirow{3}{*}{ BAP } & 0.5 & $2.0 \pm 0.2 b$ & $1.9 \pm 0.1 \mathrm{~d}$ \\
\hline & 1.0 & $2.5 \pm 0.2 \mathrm{a}$ & $2.6 \pm 0.1 b$ \\
\hline & 2.0 & $1.6 \pm 0.2 \mathrm{c}$ & $2.1 \pm 0.2 \mathrm{~cd}$ \\
\hline \multirow{3}{*}{ Zeatin } & 0.5 & $1.3 \pm 0.1 \mathrm{~cd}$ & $2.4 \pm 0.1 b c$ \\
\hline & 1.0 & $1.4 \pm 0.1 \mathrm{~cd}$ & $2.9 \pm 0.2 \mathrm{a}$ \\
\hline & 2.0 & $1.6 \pm 0.1 \mathrm{c}$ & $3.0 \pm 0.3 \mathrm{a}$ \\
\hline \multirow{3}{*}{ Kinetin } & 0.5 & $1.0 \pm 0.0 \mathrm{~d}$ & $1.3 \pm 0.1 \mathrm{e}$ \\
\hline & 1.0 & $1.0 \pm 0.0 \mathrm{~d}$ & $1.4 \pm 0.1 \mathrm{e}$ \\
\hline & 2.0 & $1.0 \pm 0.0 \mathrm{~d}$ & $1.3 \pm 0.1 \mathrm{e}$ \\
\hline
\end{tabular}

Mean separation within columns by Duncan's multiple range test at the $5 \%$ level.

\section{Shoot multiplication}

To study the impact of medium supplementation on multiple shoot induction, shoot tip explants were cultured on MS medium with varying concentrations of BAP, zeatin, or kinetin $(0.0,0.5,1.0$ and $2.0 \mathrm{mg} / \mathrm{L})$. After 6 weeks of culture, there were significant differences both between cytokinin types and cytokinin concentrations in terms of the mean number of shoots per explant and the mean shoot length (Table 2). The highest number of shoots per explant (2.5) was obtained on MS medium containing 1.0 $\mathrm{mg} / \mathrm{L}$ BAP, and the highest average maximum shoot length $(3.0 \mathrm{~cm})$ was obtained on MS medium containing $2.0 \mathrm{mg} / \mathrm{L}$ zeatin. The addition of kinetin to the medium did not induce multiple shoot formation. Overall, BAP was more effective for multiple shoot induction from shoot tip explants relative to the other cytokinins (zeatin and kinetin). Thus, BAP appears to have a significant beneficial effect on multiple shoot induction of T. mandshurica, with an optimal concentration of $1.0 \mathrm{mg} / \mathrm{L}$.

The stimulatory effect of cytokinins on shoot multiplication from shoot tip and axillary bud explants in vitro have been described for decades and are a core element of propagation research. However, the response of explants from different plants varies depending on the type and concentration of cyokinin. In a comparison of BAP and kinetin in Cucumis sativus, BAP $(1.0 \mathrm{mg} / \mathrm{L})$ was more effective at increasing the number of shoots developed from shoot tip explants. However, lower concentrations of BAP and kinetin (below $0.5 \mathrm{mg} / \mathrm{L}$ ) did not promote shoot induction (Vasudevan et al. 2002). In Chlorophytum borivilianum, BAP $(2.0 \sim 6.0 \mathrm{mg} / \mathrm{L})$ leads to a significant increase in shoot multiplication, and kinetin $(2.0 \sim 6.0 \mathrm{mg} / \mathrm{L})$ significantly increases shoot elongation (Ashraf et al. 2014). In Ficus carica, BAP is more effective for multiple shoot induction from shoot tip explants as compared to zeatin and its optimum concentration was $2 \mathrm{mg} / \mathrm{L}$ (Ling et al. 2018). In Scutellaria alpine, a comparison of BAP, kinetin, zeatin, and TDZ, found that BAP $(0.5 \sim 1.0 \mathrm{mg} / \mathrm{L})$ was the most effective for multiple shoot induction from shoot tip explants (Grzegorczyk-Karolak et al. 2015). In Betula lenta, BAP $(1.0 \mathrm{mg} / \mathrm{L})$ is more effective for shoot multiplication from shoot tip segments than 2-iP and TDZ (Rathwell et al. 2016). In the present study, among the cytokinins tested, BAP $(1.0 \mathrm{mg} / \mathrm{L})$ was most effective at inducing multiple shoots from shoot tip explants, but zeatin $(2.0 \mathrm{mg} / \mathrm{L})$ was most effective when compared on the basis of shoot elongation. However, treatment with kinetin did not promote shoot multiplication. These results indicate that BAP significantly improves multiple shoot induction from shoot tip explants, however the ideal concentration may vary depending on the plant species.

In vitro rooting and ex vitro acclimatization

To investigate the effect of auxin type and concentration on rooting of $T$. mandshurica, in vitro-elongated shoots were cultured on half MS medium supplemented with different concentrations of IBA or NAA $(0.5,1.0,2.0$, and $3.0 \mathrm{mg} / \mathrm{L}$ ). As shown in Table 3 and Figure 2, there were significant differences in rooting percentage, number of roots per explant, and root length among the different auxin treatment groups. The optimum concentration was different in each auxin treatment. The highest rooting percentages $(100 \%)$ were obtained in $1 / 2$ MS medium containing $0.5 \sim 1.0 \mathrm{mg} / \mathrm{L}$ IBA or $3.0 \mathrm{mg} / \mathrm{L} \mathrm{NAA}$ after 3 
Table 3 Effect of auxin type and concentration on rooting in in vitro-elongated shoots after 3 weeks of culture

\begin{tabular}{|c|c|c|c|c|}
\hline \multicolumn{2}{|c|}{$\begin{array}{l}\text { Auxin concentration } \\
(\mathrm{mg} / \mathrm{L})\end{array}$} & $\begin{array}{l}\text { Rooting } \\
\quad(\%)\end{array}$ & $\begin{array}{l}\text { Number. of roots } \\
\text { per explant }\end{array}$ & $\begin{array}{l}\text { Length of root } \\
(\mathrm{cm})\end{array}$ \\
\hline \multicolumn{2}{|r|}{ Control } & $53.3 \pm 0.7 f$ & $1.3 \pm 0.2 \mathrm{e}$ & $3.7 \pm 0.3 \mathrm{a}$ \\
\hline \multirow{4}{*}{ IBA } & 0.5 & $100.0 \pm 0.0 \mathrm{a}$ & $6.8 \pm 0.8 \mathrm{bcd}$ & $2.6 \pm 0.1 b$ \\
\hline & 1.0 & $100.0 \pm 0.0 \mathrm{a}$ & $10.4 \pm 1.1 \mathrm{~b}$ & $1.7 \pm 0.1 \mathrm{~d}$ \\
\hline & 2.0 & $93.3 \pm 0.6 b$ & $16.1 \pm 2.2 \mathrm{ab}$ & $1.0 \pm 0.1 \mathrm{e}$ \\
\hline & 3.0 & $86.7 \pm 0.7 \mathrm{c}$ & $19.6 \pm 3.2 \mathrm{a}$ & $0.8 \pm 0.1 \mathrm{e}$ \\
\hline \multirow{4}{*}{ NAA } & 0.5 & $66.7 \pm 0.5 \mathrm{e}$ & $2.7 \pm 0.4 \mathrm{de}$ & $2.2 \pm 0.2 \mathrm{c}$ \\
\hline & 1.0 & $83.3 \pm 0.7 d$ & $4.2 \pm 0.5 \mathrm{cde}$ & $2.4 \pm 0.2 b c$ \\
\hline & 2.0 & $91.7 \pm 0.6 b$ & $5.8 \pm 0.5 \mathrm{bcde}$ & $1.7 \pm 0.1 \mathrm{~d}$ \\
\hline & 3.0 & $100.0 \pm 0.0 \mathrm{a}$ & $8.9 \pm 0.9 b c$ & $1.6 \pm 0.1 \mathrm{~d}$ \\
\hline
\end{tabular}

Mean separation within columns by Duncan's multiple range test at the $5 \%$ level.

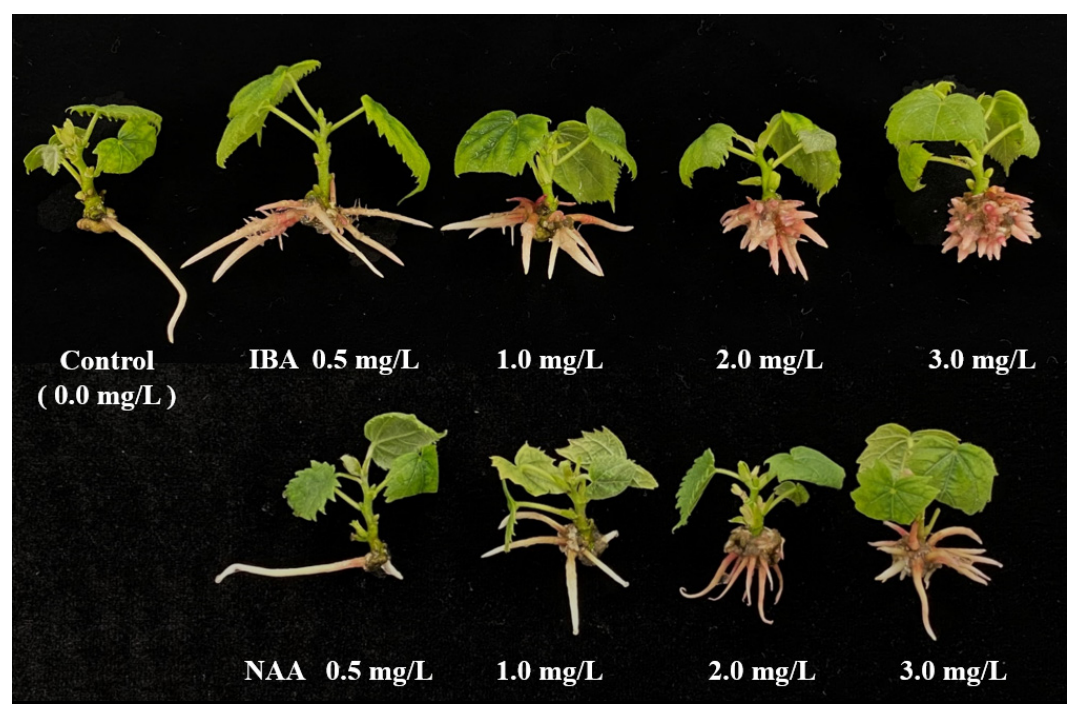

Fig. 2 The rooting of Tilia mandshurica shoots in vitro that were cultured in half-strength Murashige and Skoog (MS) medium supplemented with various concentrations of indole-3-butyric acid (IBA) or 1-naphthaleneacetic acid (NAA) after 3 weeks of culture

weeks of culture. The control medium without any auxin supply led to the lowest rooting percentage (53.3\%). The medium with $3.0 \mathrm{mg} / \mathrm{L}$ IBA induced the highest number of roots per explant (19.6) but affected the root growth negatively. Interestingly, the highest root length $(4.7 \mathrm{~cm})$ was achieved in the control medium lacking auxins (IBA or NAA). Considering these data, the lower concentrations $(0.5 \sim 1.0 \mathrm{mg} / \mathrm{L})$ of IBA and highest concentration $(3.0$ $\mathrm{mg} / \mathrm{L}$ ) of NAA were more effective for rooting shoots of T. mandshurica in vitro.

During acclimatization, we sought to determine the extent of growth of plantlets (Fig. 2) that had been rooted on auxin (IBA or NAA)-supplemented vs. auxin-free medium after transplantation to plastic containers containing an artificial soil mixture (Fig. 3A-3C). As shown in Table 3 and Fig. 3C. the highest survival rate (100\%) was seen in plantlets that were rooted in media with $0.5 \sim 1.0 \mathrm{mg} / \mathrm{L}$
IBA or NAA. However, plantlets rooted in media with higher concentrations (up to $3.0 \mathrm{mg} / \mathrm{L}$ ) of IBA or NAA resulted in a lower survival rate $(86.7 \%$ or $87.7 \%$, respectively). The greatest root length $(18.5 \mathrm{~cm})$ was obtained in plantlets rooted in medium with $0.5 \mathrm{mg} / \mathrm{L}$ IBA. These results suggest that IBA is a good root-inducing agent for the establishment of T. mandshurica plantlets in the soil, and low concentrations of IBA $(0.5 \sim 1.0 \mathrm{mg} / \mathrm{L})$ are sufficient for both in vitro rooting and acclimatization.

Plant rooting is one of the most important stages of micropropagation and is a prerequisite to proper acclimatization in soil. Auxins like IBA, IAA, and NAA play a critical role in inducing adventitious rooting in many plants. However, the effects of auxin type and concentration on root formation vary considerably across plant species. In the olive cultivar 'Moraiolo,' in a comparison of IBA and NAA, IBA at a concentration of $1.5 \mathrm{mg} / \mathrm{L}$ was superior 


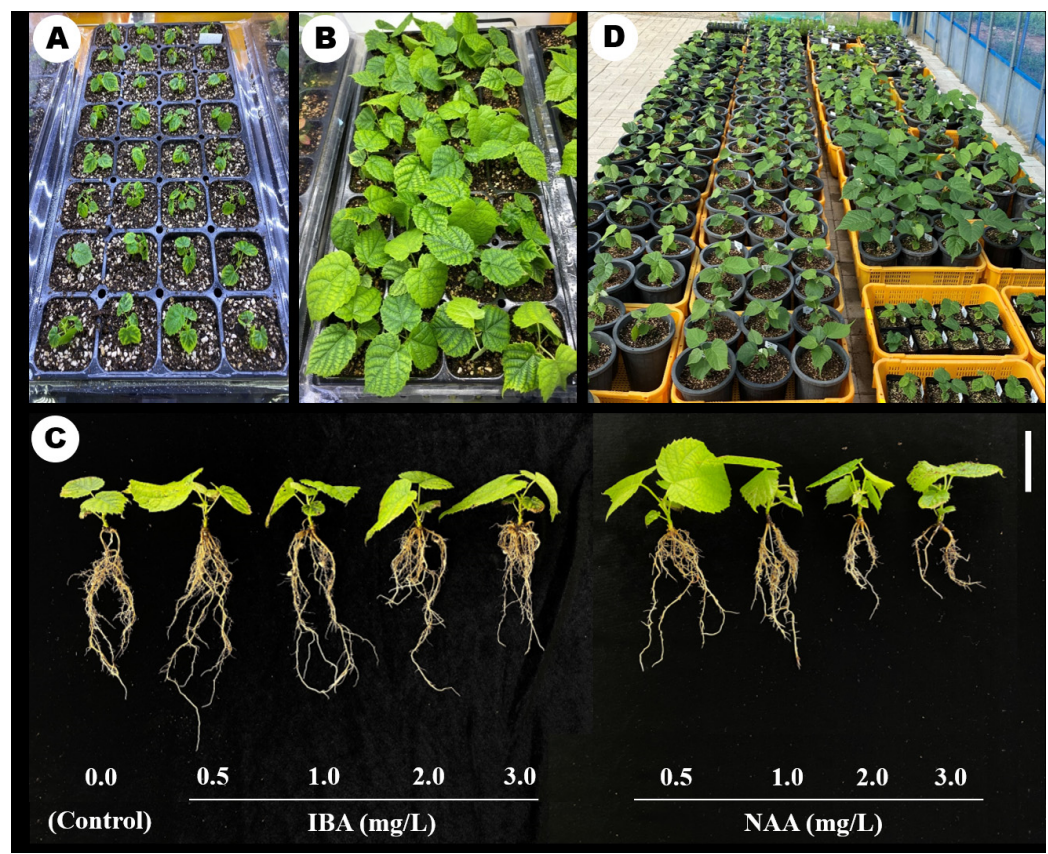

Fig. 3 The acclimatization of Tilia mandshurica plantlets that were rooted on half-strength Murashige and Skoog (MS) medium supplemented with or without auxin (IBA or NAA). (A) Plantlets transplanted in plastic containers with soil. (B) Plants acclimatized in plastic containers with soil for 5 weeks. (C) Comparison of the growth of plantlets rooted on auxin (IBA or NAA)-supplemented and auxin-free media after 5 weeks of acclimatization. Scale bar $=5 \mathrm{~cm}$. (D) Cultivation of potted plants in the greenhouse

Table 4 Growth characteristics of Tilia mandshurica plantlets that were rooted in half-strength Murashige and Skoog (MS) medium supplemented with auxin (IBA or NAA) after 6 weeks of acclimatization

\begin{tabular}{|c|c|c|c|}
\hline \multicolumn{2}{|c|}{$\begin{array}{c}\text { Auxin concentration } \\
(\mathrm{mg} / \mathrm{L})\end{array}$} & $\begin{array}{l}\text { Survival } \\
(\%)\end{array}$ & $\begin{array}{l}\text { Length of root } \\
(\mathrm{cm})\end{array}$ \\
\hline \multicolumn{2}{|c|}{ Control } & $100.0 \pm 0.0 \mathrm{a}$ & $16.4 \pm 0.9 \mathrm{abc}$ \\
\hline \multirow{4}{*}{ IBA } & 0.5 & $100.0 \pm 0.0 \mathrm{a}$ & $18.5 \pm 0.8 \mathrm{a}$ \\
\hline & 1.0 & $100.0 \pm 0.0 \mathrm{a}$ & $17.6 \pm 1.5 \mathrm{ab}$ \\
\hline & 2.0 & $93.3 \pm 0.5 b$ & $16.9 \pm 0.9 \mathrm{abc}$ \\
\hline & 3.0 & $86.7 \pm 0.6 \mathrm{~d}$ & $13.5 \pm 0.8 \mathrm{bcde}$ \\
\hline \multirow{4}{*}{ NAA } & 0.5 & $100.0 \pm 0.0 \mathrm{a}$ & $14.8 \pm 2.1 \mathrm{abcd}$ \\
\hline & 1.0 & $100.0 \pm 0.0 \mathrm{a}$ & $12.6 \pm 1.4 \mathrm{cde}$ \\
\hline & 2.0 & $88.5 \pm 0.9 c$ & $11.4 \pm 2.3 \mathrm{de}$ \\
\hline & 3.0 & $87.5 \pm 0.5 \mathrm{~cd}$ & $10.0 \pm 1.8 \mathrm{~d}$ \\
\hline
\end{tabular}

Mean separation within columns by Duncan's multiple range test at the $5 \%$ level.

for rooting. Moreover, the roots produced on IBA were longer, with better quality shoots, and NAA led to a poor response with necrotic leaves and leaf abscission (Ali et al. 2009). In Paulownia elongata, IBA was more effective for in vitro rooting than other auxins (IAA and NAA) in terms of well-developed roots, and its optimum concentration was $0.5 \mathrm{mg} / \mathrm{L}$ (Zayova et al. 2014). In Chrysanthemum morifolium Ramat, $1 \mathrm{mg} / \mathrm{L}$ IBA induced the highest number (5.7) of roots per explant among three auxin types that were tested (IBA, IAA, and NAA). The greatest root length $(36.2 \mathrm{~mm})$ was achieved in medium with $1 \mathrm{mg} / \mathrm{L} \mathrm{IAA}$, and
NAA was associated with fewer and shorter roots (Chae 2016). In Crocosmia $\times$ crocosmiiflora 'Lucifer,' IBA at a concentration of $1.0 \mathrm{mg} / \mathrm{L}$ increased root number and length relative to growth with IAA or NAA (Krupa-Małkiewicz and Żurawik 2017). In Amelanchier alnifolia, NAA was superior for rooting compared to IBA and IAA, and it's proper concentration was $1.0 \mathrm{mg} / \mathrm{L}$ (Júlia and Alena 2019). In studies of in vitro adventitious root formation of Bienertia sinuspersici cuttings, medium containing $5.0 \mathrm{mg} / \mathrm{L}$ NAA led to the highest number of roots, but medium supplemented with $1.0 \mathrm{mg} / \mathrm{L}$ IBA produced the longest 
roots (Northmore et al. 2015). In the present study, auxin type (IBA or NAA) and concentrations $(0.5 \sim 3.0 \mathrm{mg} / \mathrm{L})$ both had significant effects on in vitro rooting and acclimatization of T. mandshurica. Maximum rooting (100\%) was observed when shoots were cultured in half-strength MS medium supplemented with $0.5 \sim 1.0 \mathrm{mg} / \mathrm{L}$ IBA or 3.0 $\mathrm{mg} / \mathrm{L}$ NAA. During acclimatization, plantlets that had been rooted on $0.5 \mathrm{mg} / \mathrm{L}$ IBA-supplemented medium had the longest roots $(18.5 \mathrm{~cm})$ as well as the highest rate of survival $(100 \%)$. These results indicate that IBA is effective for the rooting and acclimatization of $T$. mandshurica in terms of root growth and plantlet survival.

In conclusion, these studies sought to identify which growth conditions would most strongly support the development of shoots. In our experiments comparing the effect of different concentrations of BAP $(0 \sim 2.0 \mathrm{mg} / \mathrm{L})$ on the extent of shoot induction from juvenile or mature stock plants, we found that BAP at a concentration of $1.0 \mathrm{mg} / \mathrm{L}$ was ideal for the stimulation of shoot induction from apical bud explants obtained from juvenile seedlings (5-month-old), but had no effect on explants from mature plants. Further analysis of the efficacy of three cytokinins for improving multiple shoot induction from shoot tip explants found that BAP at $1.0 \mathrm{mg} / \mathrm{L}$ provided the best results. During plant regeneration and soil acclimatization, half-strength MS medium supplemented with $0.5 \mathrm{mg} / \mathrm{L}$ IBA resulted in optimal initiation and growth of plantlet roots. Plantlets that were rooted on the medium with $0.5 \mathrm{mg} / \mathrm{L} \mathrm{IBA}$ were successfully acclimatized on artificial soil with a survival rate of $100 \%$. This system for rapid T. mandshurica shoot multiplication and regeneration system may find uses in large-scale propagation in support of the honey and timber industries.

\section{References}

Ashraf MF, Aziz MA, Kemat N, Ismail I (2014) Effect of cytokinin types, concentrations and their interactions on in vitro shoot regeneration of Chlorophytum borivilianum Sant. \& Fernandez. Electronic Journal of Biotechnology 17:275-279

Ali A, Ahmad T, Abbasi NA, Hafiz IA (2009) Effect of different concentrations of auxins on in vitro rooting of olive cultivar 'Moraiolo'. Pak. J. Bot. 41(3):1223-1231

Basto S, Serrano C, Hodson de Jaramillo E (2012) Effects of donor plant age and explants on in vitro culture of Cedrela montana Moritz ex Turcz. Univ. Sci. 17(3):263-271

Chalupa V (1990) Plant regeneration by somatic embryogenesis from cultured immature embryos of oak (Quercus robur L.) and linden (Tilia cordata Mill.). Plant Cell Rep 9:398-401

Chae SC (2016) Influence of auxin concentration on in vitro rooting of Chrysanthemum Morifolium Ramat. Biosci Biotech
Res Asia 13(2)

Grzegorczyk-Karolak I, Kuz'ma Ł, Wysokin'ska H (2015) The effect of cytokinins on shoot proliferation, secondary metabolite production and antioxidant potential in shoot cultures of Scutellaria alpina. Plant Cell Tiss Organ Cult 122:699-708

Júlia H, Alena G (2019) In vitro rooting and acclimatization of Amelanchier alnifolia (Nutt.) Nutt. ex M. Roem: Testing of auxin, spermidine, and gibberellin for overcoming dormancy. Journal of Berry Research 9(3):549-561

Kim JH, Moon HK, Park JI, Lee BC (1988) Somatic embryogenesis and plant regeneration in callus from hypocotyl segments of Tilia amurensis. In: Genetic Manipulation of Woody Plants. JW Hanover and DE keathley (eds) Plenum Press, New York, pp 473-474

Kim TD, Choi YE, Lee BS, Kim YJ, Kim TS, Kim IS (2006) Micropropagation of Tilia amurensis via Repetitive Secondary Somatic Embryogenesis. J Plant Biotechnol 33(4):243-248

Kim TD, Lee BS, Kim TS, Choi YE (2007) Developmental plasticity of glandular trichomes into somatic embryogenesis in Tilia amurensis. Ann Bot. 100(2):177-83

Krupa-Małkiewicz M, Żurawik P (2017) In vitro rooting of Crocosmia $\times$ crocosmiiflora 'Lucifer'. Folia Hort. 29(1):3-10

Lee DK, Suh MH (1989) Propagation of Tilia species by cutting. Kor J Apiculture 4:56-60

Ling WT, Liew FC, Lim WY, Subramaniam S, Chew BL (2018) Shoot induction from axillary shoot tip explants of fig (Ficus carica) cv. Japanese BTM 6. Tropical Life Sciences Research 29(2):165-174

Morsink WAG, Smith VG (1974) Root and shoot development on cuttings of basswood (Tilia Americana) as affected by auxin treatments and size cuttings. Can J For Res 4:246-249

Morsink WAG, Smith VG (1975) The effect of some monohydroxybenzoic and dihyroxybenzoic acids as auxin synergists on rooting softwood cuttings of basswood (Tilia Americana) L.) under mist. Can J For Res 5:500-502

Moon HK, Youn Y (1996) Somatic embryogenesis and plant regeneration from cultured immature zygotic embryos of Tilia mandshurica Rupr. Res Rep For Gen Res Inst Korea 32:64-71

Moon HK, Noh EW, Ha YM, Shim KK (2002) Micropropagation of Juvenile and Mature Tree of Corylopsis coreana by Axillary Bud Culture. Journal of Plant Biotechnology 29(2):117-121

Murashige T, Skoog F (1962) A revised medium for rapid growth and bioassays with tobacco tissue cultures. Physiol. Plant. 15:473-97

Northmore JA, Leung M, Chuong SDX (2015) Effects of Media Composition and Auxins on Adventitious Rooting of Bienertia sinuspersici Cuttings. Advances in Bioscience and Biotechnology 6:629-636

Panchev V (2019) Seed propagation of Tilia sp. - agrobiological and technological aspects. Agrarni Nauki 11(25):33-40

Rathwell R, Shukla MR, A. Jones MP, Saxena PK (2016) In vitro propagation of cherry birch (Betula lenta L.). Can. J. Plant Sci. 
96: $571-578$

Srinidhi HV, Gill RIS, Sidhu DS (2008) Micropropagation of Adult and Juvenile Neem (Azadirachta indica A. Juss). Journal of Crop Improvement 21(4):221-232

Tawfik AA, Ibrahim OH, Taha MA (2020) Micropropagation of Koelreuteria bipinnata Using Juvenile and Mature Explants Current Applied Science and Technology 20(3):470-478

Üçler AÖ, Mollamehmetoğlu N (2001) In vitro Plantlet Regeneration from Mature Embryos of Linden (Tilia platyphyllos Scop.) and Multiplication of its Buds. Turk J Agric For 25:181-186

Vasudevan A, Selvaraj N, Periyasamy S, Ganapathi A (2002) Multiple shoot induction from the shoot tip explants of cucumber (Cucumis sativus L.). Cucurbit Genetics Cooperative Report 24:8-12

Youn Y, Ohba K (1990) In vitro plantlet regeneration from axillary buds of Tilia amurensis mature trees and clonal variation in tissue culturability. J Kor For Soc 79:109-114
Youn Y, Ishii K, Saito A, Ohba K (1988) In vitro plantlet regeneration from axillary buds of mature trees of Tilia cordata. J Jpn For Soc 70:315-317

Yoon, TS, Lim, JY, Kim JJ (2005) Growth of Mandshurian Linden (Tilia mandshurica Pupr. et Max.) Seedlings as Affected by Container Types and Volumes. The Korean Society for BioEnvironment Control. 14(4):238-243

Yang Y, Haoran S, Li J, Lixue Y (2020) Effects of exponential fertilization on growth and root morphology of Tilia amurensis seedlings. Journal of Nanjing Forestry University (Natural Sciences Edition) 44(2)

Yang LX, Wang HN, Shen HL (2011) Reproduction Techniques for hardwood cutting of Tilia amurensis. Advanced Materials Research 183-185

Zayova E, Petrova M, Dimitrova L, Vasilevska-Ivanova R, Stoeva D (2014) Effect of different auxins on in vitro rooting of Paulownia elongata plants. Genetics and Plant Physiology 4 (3-4):155-162 